\title{
PRÁTICAS DE LETRAMENTO ACADÊMICO NO FACEBOOK
}

\author{
Raquel Aparecida Soares Reis Franco* \\ Instituto Federal de Minas Gerais \\ Belo Horizonte, Minas Gerais, BR \\ Maria Lúcia Castanheira ${ }^{* *}$ \\ Universidade Federal de Minas Gerais \\ Belo Horizonte, Minas Gerais, BR
}

\begin{abstract}
Resumo
Neste texto, analisamos práticas de letramento acadêmico e digital desenvolvidas por participantes de um curso de especialização em Linguagem e Tecnologia. Exploramos uma abordagem social do letramento e dos Letramentos Acadêmicos (LEA; STREET, 1998; LILLIS; SCOTT, 2007) para examinar quais os textos foram produzidos pelos participantes do curso durante disciplinas que utilizaram o Facebook como Ambiente Virtual de Aprendizagem (AVA). Este estudo é de natureza qualitativa e interpretativa e integra pesquisa mais ampla que envolveu a realização de observação participante em um curso de especialização em uma instituição pública federal brasileira, durante os anos de 2012 e 2013. A análise das condições de produção da escrita nesse contexto de formação evidenciaram que as práticas de escrita desenvolvidas pelos participantes foram orientadas pelo "modelo de habilidades" (LEA \& STREET, 1998), dando lugar à "prática do mistério" (LILLIS; SCOTT, 2007). Dentre outros aspectos observados, destaca-se que a escrita de professores caracteriza-se como híbrida, apresentando traços de gêneros textuais presentes no Facebook e traços de gêneros textuais de natureza escolar.
\end{abstract}

Palavras-chave: Letramento Acadêmico; Práticas de Escrita; Formação Continuada.

\section{ACADEMIC LITERACY PRACTICES ON FACEBOOK}

\begin{abstract}
In this paper, we analyze academic and digital literacies practices developed by paticipants of a Language and Technology developmental program. We adopt a social and academic literacies approach (LEA; STREET, 1998; LILLIS; SCOTT, 2007) to examine what texts participants write in disciplines that use Facebook as a learning platform. The reportedstudyisofaqualitativeandinterpretivenature. Theeventshereinanalyzedintegratethedatabankofaresearch project that involved participant observation developed throughout the years of 2012 and 2013 in a Brazilian profes sional graduate program. The analysis makes visible that literacy practices developed by participants are oriented by the "skills model" (Lea \& Street, 1998), which leads to the "institutional practice of mystery" (LILLIS; SCOTT, 2007). In this context, it is interesting to note that teachers' writings can be characterized as a hybrid of scholastic genres and Facebook genres.
\end{abstract}

Keywords: Academic Literacy; Digital Literacies; Writing Practices; Continuing Education.

\footnotetext{
Professora do Instituto Federal de Educação, Ciência e Tecnologia de Minas Gerais. Doutorado em Educação pela linha de pesquisa Educação e Linguagem da Universidade Federal de Minas Gerais. Seu endereço de email é raquel.franco@ifmg.edu.br

"Professora Titular da Faculdade de Educação da Universidade Federal de Minas. Doutorado em Filosofia da Educação pela Universidade da Califórnia, Santa Barbara. Seu endereço de email é lalucia@gmail.com
} 


\section{Introdução}

As análises e as reflexões apresentadas neste texto exploram proposições e indagações sobre o uso de Novas Tecnologias de Informação e Comunicação (NTIC) e sobre práticas de letramento acadêmico desenvolvidos em processos de formação de profissionais da educação. Nessa perspectiva, analisaremos o que e para que professores e alunos de um curso de especialização em Linguagem e Tecnologia escrevem em disciplinas desenvolvidas através do uso NTIC, mais especificamente em disciplinas em que o FACEBOOK foi utilizado como Ambiente Virtual de Aprendizagem (AVA).

Ao longo dos últimos anos, temos observado mudanças no campo da escrita e da leitura resultantes da crescente integração das NTIC à nossa rotina social e profissional. $\mathrm{O}$ entendimento de que a escola não pode ficar alheia a essas mudanças leva à defesa de que é necessário explorar novos recursos tecnológicos nos processos de ensino, de maneira a promover a produção e a disseminação de conhecimento. Ações para democratizar o acesso ao conhecimento e promover o letramento digital têm sido incentivadas por agências internacionais (UNESCO, 2016) e propostas em documentos oficiais brasileiros, como, por exemplo, no Plano Nacional de Educação (PNE) (BRASIL, 2001). Nessa perspectiva, o PNE/2001 estabeleceu que cursos de formação de profissionais da educação devem promover o domínio das NTIC e a sua integração à prática do magistério. O Programa Nacional de Formação Continuada em Tecnologia Educacional (ProInfo Integrado) do Ministério da Educação do Brasil é um exemplo de políticas educacionais desenvolvidas nessa direção. Nesse contexto, vimos um significativo aumento do número de cursos de especialização lato sensu e o crescente incentivo ao uso de NTIC em cursos de formação profissional inicial e continuada.

Notamos, entretanto, que diversos estudos têm indicado que a implementação de políticas para integração de NTIC tem se dado por meio de "ações isoladas e iniciativas de alguns profissionais que adotam a tecnologia em suas práticas pedagógicas e empreendem ações de difusão" (PAIVA, 2013, p.7). Conforme pontuam Barreto et al (2006), com base nos resultados de análise de recorte do estado do conhecimento em educação e tecnologia, produzido a partir de 331 documentos (242 dissertações, 47 teses e 42 artigos) elaborados entre 1996 e 2002, "adquirem relevo propostas de 'virtualização' do ensino, expressando a aprendizagem por meios eletrônicos, redimensionando as categorias tempo espaço e, nesses termos, apontando para a ruptura com a demarcação da sala de aula e da escola, pelo menos na configuração histórica conhecida por todos".

Considerando um cenário mais abrangente, é possível identificar que, paralelamente ao movimento desenvolvido em direção ao uso das NTIC nos processos de ensino, foi sendo constituído um campo de estudo sobre práticas de letramento acadêmico (LEA; STREET, 1998; LILLIS; SCOTT, 2007) que analisa como e para que a escrita é utilizada no contexto acadêmico, suas implicações para o estabelecimento de relações de poder, construções identitárias e concepções relativas ao ensino da escrita na universidade.

Tomando, então, como referência proposições e questões advindas de estudos sobre usos NTIC em processos educativos e Letramentos Acadêmicos, esse artigo lança luzes, sobre um curso de especialização lato sensu para professores e profissionais da educação. A relevância desse trabalho justifica-se quando consideramos pelo menos dois aspectos: primeiro, os temas discutidos em cursos de especialização e segundo, o perfil dos seus alunos.

Com relação ao primeiro aspecto, ao se realizar o levantamento de cursos de especialização ofertados na região metropolitana de Belo Horizonte, foram identificados nove cursos, dos quais sete voltam-se para o campo da linguagem, com ênfase em linguagem e tecnologia, docência no ensino superior, novas linguagens e novas abordagens, língua portuguesa, leitura, escrita e gramática, língua portuguesa no ensino fundamental. A análise do ementário desses cursos evidenciou que: "produção textual", "utilização e criação de práticas necessárias para o desenvolvimento de habilidades de leitura e escrita", "letramento digital em Língua Portuguesa e Metodologia de Pesquisa e Projetos", "alternativas de trabalho referentes às práticas escolares de ensino de leitura e produção de textos", "a estrutura e o gênero textual em Língua Portuguesa” constituem 
temáticas recorrentes nesses sete cursos de especialização. Tal ocorrência nos levou a indagar como tais temáticas têm sido contempladas e quais significados são atribuídos à escrita nesse contexto de formação, seja quando a escrita é o objeto de estudo focalizado, seja quando a escrita integra as práticas de ensino promovidas nesse contexto. Ademais, nos leva também a indagar se e de que forma tais aspectos são explorados articuladamente com o uso de NTIC.

Quanto ao perfil dos profissionais atendidos nos cursos de especialização lato sensu, identificamos a presença tanto de especialistas ou professores experientes, como de profissionais em fase inicial de inserção no mercado de trabalho educacional. Entre esses profissionais são encontrados responsáveis pelo planejamento e desenvolvimento do currículo em escolas públicas ou privadas do país, coordenadores de atividades pedagógicas e professores de várias disciplinas curriculares (por exemplo, Língua Portuguesa, História, Geografia, Matemática), além de profissionais que poderão ser responsáveis por essas atividades após inserção no mercado de trabalho. Dessa forma, direta ou indiretamente, esses profissionais são, ou poderão vir a ser, responsáveis por promover atividades de produção textual nos processos de ensino de disciplinas variadas em diferentes níveis de ensino. Há, obviamente, expectativa de que tais cursos possam contribuir para promover uma melhora da qualidade do ensino nos diferentes níveis de escolarização e, por extensão, do trabalho com a escrita nas escolas públicas e privadas brasileiras.

Considerando essas questões relativas às temáticas contempladas em cursos de especialização e o perfil dos alunos desses cursos, parece-nos legítimo esperar dos cursos de especialização a possibilidade de refletir sobre o lugar ocupado pela produção escrita e os usos de NTIC nos processos de ensino, seja como objeto de ensino e aprendizagem, seja como recurso utilizado para o ensino e a avaliação de outros conteúdos curriculares. Tendo em vista a necessidade de conhecer de maneira mais aprofundada como tais aspectos têm sido implementados em cursos dessa natureza foi desenvolvida uma pesquisa, de perspectiva etnográfica (GREEN; BLOOME, 1997), realizada durante os anos de 2012 e 2013. A análise apresentada a seguir integra, portanto, um estudo mais abrangente, que examinou os significados da escrita e suas articulações com o uso de NTIC em curso de especialização sobre Linguagem e Tecnologia (doravante LINTEC). Neste artigo, privilegiaremos a abordagem das seguintes questões: Quais as práticas de escrita construídas no Facebook enquanto AVA? O que participantes da pesquisa escreveram? Com que propósito? Quais os gêneros textuais solicitados aos alunos? A partir da abordagem dessas questões, esperamos contribuir para a compreensão dos usos da escrita associados ao uso de NTIC no contexto da formação de professores.

Nas próximas seções, discutiremos, ainda que brevemente, alguns aspectos das abordagens dos Letramentos Acadêmicos e letramentos digitais que foram explorados no desenvolvimento da análise apresentada a seguir.

\section{Letramentos Acadêmicos}

O campo de estudos denominado Letramentos Acadêmicos explora contribuições de vários campos disciplinares e subcampos: linguística aplicada e sociolinguística, antropologia, teoria sociocultural da aprendizagem, novos estudos de alfabetização e estudos do discurso (LILLIS e SCOTT, 2007) no exame das práticas de escrita no contexto universitário. Pesquisadores desse campo concebem o letramento como prática social e proclamam ser o letramento mais que o conhecimento do código da língua per se, mas se refere aos usos e às funções da escrita dentro das práticas sociais em que se insere (LEA; STREET, 1998; STREET, 2003).

Um dos estudos considerados como referência inicial na constituição desse campo de estudo foi realizado por Lea e Street (1998), sendo que as proposições feitas a partir desse trabalho continuam sendo referência teórica e analítica ainda hoje. Esses pesquisadores realizaram um projeto de pesquisa empírica em duas universidades distintas, no Reino Unido, examinando os textos dos alunos em um contexto de práticas institucionais, relações de poder e identidades. Esse estudo possibilitou a identificação de lacunas na forma como alunos e professores compreendem os requisitos da produção textual, e levou à descrição de três modelos de ensino da produção textual no contexto universi- 
tário, que denominaram de habilidades cognitivas, socialização acadêmica e letramentos acadêmicos.

O modelo de estudo das habilidades cognitivas compreende que "a escrita e o letramento são habilidades individuais e cognitivas e focaliza as características linguístico-discursivas, presumindo que o estudante possa fazer transferências desse conhecimento de um contexto para outro". Nesse modelo a escrita é tomada como um conjunto de habilidades atomizadas que os estudantes devem aprender e que, depois, são transferíveis para outros contextos. O aluno é visto a partir do seu déficit durante a correção de seu texto, ou seja, a partir daquilo que ele não sabe e precisa aprender, de modo que a redação é tomada como o reflexo de habilidades técnicas e instrumentais de uso da língua. O foco é sobre as tentativas de «consertar» os problemas concernentes à aprendizagem do aluno tratados como um tipo de patologia. Baseia-se na teoria da linguagem que enfatiza as características da superfície, da gramática e da ortografia. Suas fontes se encontram na psicologia comportamental e nos programas de treinamento que conceituam a escrita do estudante de modo tecnicista, ou seja, meramente instrumental (LEA; STREET, 1998).

O modelo de socialização acadêmica, de acordo com Lea e Street (1998), trata da aculturação dos discursos e dos gêneros específicos das disciplinas e dos conteúdos. Dessa forma, o professor é o principal responsável por introduzir os alunos na cultura universitária, a fim de que eles assimilem os modos de falar, raciocinar, interpretar e usar as práticas de escrita, valorizadas nas disciplinas e áreas temáticas da universidade. O modelo parte da concepção de que os gêneros discursivos acadêmicos são relativamente homogêneos e, uma vez que o aluno aprende as convenções que regulam esses gêneros, estará habilitado a se engajar nas práticas letradas que permeiam essa instância. O foco está na orientação de estudantes para a aprendizagem e interpretação de tarefas de aprendizagem, fundamentando-se assim na psicologia social, na antropologia e na educação construtivista. A tarefa do professor é a de promover o processo de inserção dos alunos em uma "cultura" nova, a da academia.
Em oposição ao enquadramento instrumental dos dois modelos anteriores, o terceiro modelo, letramentos acadêmicos, diz respeito ao fazer sentido, à identidade, ao poder, à autoridade e aos princípios de natureza institucional, logo políticos e ideológicos envolvidos no processo de escrita. Nesse modelo, a atenção está centrada nos adequados e efetivos usos do letramento como questões epistemológicas mais complexas, dinâmicas, situadas e que envolvem processos sociais como as relações de poder entre pessoas e instituições, além de questões de identidades sociais (LEA; STREET, 1998). Para Lillis e Scott (2007), o modelo dos letramentos acadêmicos questiona o mito da homogeneidade dos discentes, da estabilidade das disciplinas e da relação unidirecional professor-estudante. Contrapõe-se, assim, ao discurso do déficit que, no Reino Unido, surgiu num contexto de expansão do sistema de Ensino Superior, cuja diversidade de estudantes locais e internacionais passou a ser vista como um "problema".

Uma das pesquisas realizadas no contexto descrito acima eque rejeita essa visão de "problema" e/ou de déficit é a de Lillis (1999). No artigo denominado Whose "Com mon Sense'? Essayist literacy and the institutional practice of mystery a pesquisadora mostra que as convenções que regulam a escrita acadêmica fazem parte do "senso comum", ou seja, são transparentes para quem faz parte da comunidade acadêmica, mas para quem intenta entrar nela não são tão transparentes assim. Essa não transparência das convenções acadêmicas foi nomeada por Lillis (1999) como "prática institucional do mistério", que emerge dos contextos e das situações específicas de aprendizagem no Ensino Superior, bem como da cultura dessa esfera. Para a pesquisadora, essa prática está alinhada ao modelo de habilidades cognitivas para o ensino da escrita. Esse modelo, tratado anteriormente, tende a reforçar a visão de que as convenções da escrita são fenômenos autônomos e facilmente identificáveis. Dessa forma, a "prática institucional do mistério" consolida-se quando não são explicitadas ao aluno as convenções que regem a escrita acadêmica e quando o professor pressupõe que o discente já as saiba. Fiad (2011, p. 363), ao tratar da crítica realizada por Lillis (1999), argumenta que a "prática institucional 
do mistério" nega o aluno real com o qual o professor está lidando, não reconhecendo como ele é. Assim, "há a negação da voz do aluno no processo de ensino-aprendizagem e há a negação ao estudante das convenções que regem a escrita acadêmica".

Pela pesquisa de Lillis (1999), observamos que o modelo dos letramentos acadêmicos tem sido um referencial de caráter crítico na identificação de lacunas quanto ao que é oferecido pelas universidades do Reino Unido (STREET, 2010, p.546). Entretanto, é importante salientar que o modelo de letramentos acadêmicos é acusado de oferecer poucas alternativas pedagógicas ao modelo de socialização acadêmica. Além disso, as pesquisas realizadas no campo dos letramentos acadêmicos são estudos de caso de pequena escala (WINGATE; TRIBBLE, 2012). Respondendo a essas críticas, Street (2012b) reconhece que "ainda há muito a ser feito com relação ao desenvolvimento das implicações pedagógicas" na área. Porém, entende que os letramentos acadêmicos oferecem uma visão mais ampla quando se trata da produção textual dos alunos e do feedback dado pelo corpo docente.

Vale dizer que embora Lea e Street (1998) realizem críticas aos modelos de habilidades cognitivas e de socialização acadêmica, os autores consideram que os modelos não se excluem, ao contrário, hibridizamse, porque privilegiam eixos de trabalho por meio dos quais os professores compreenderiam as práticas de escrita necessárias para transitar no contexto acadêmico (LEA; STREET, 1998). Apesar disso, Street (2010, p.546) argumenta que o modelo dos letramentos acadêmicos é o que melhor leva em conta "a natureza da produção textual do aluno em relação às práticas institucionais, relações de poder e identidade; em resumo, consegue contemplar a complexidade da construção de sentidos, ao contrário dos outros dois modelos".

Em nossa análise, tomamos como referência analítica as proposições e considerações acerca dos significados da escrita no contexto acadêmico, conforme discutidas acima. Buscamos, assim, examinar as condições em que os alunos produzem textos escritos em um curso de formação continuada durante a realização de disciplinas em que NTIC são exploradas. Tal análise poderá lançar luzes sobre os significados da escrita no contexto investigado, isto é, evidenciar se e como as práticas de escrita desenvolvidas pelos participantes podem ser associadas aos modelos de ensino da escrita caracterizados acima (habilidades, socialização e letramentos acadêmicos) e como essas práticas favorecem as oportunidades de aprendizagem e reflexão sobre os gêneros textuais acadêmicos, sobre os aspectos identitários e as relações de poder.

\section{Letramentos digitais}

Compreendendo as mudanças possibilitadas pelas novas tecnologias de informação e comunicação no campo da escrita e da leitura, Soares (2002) define letramento digital como um "certo estado ou condição que adquirem os que se apropriam da nova tecnologia digital e exercem práticas de leitura e de escrita na tela, diferente do estado ou condição - do letramento - dos que exercem práticas de leitura e de escrita no papel" (SOARES, 2002. p. 151).

Conforme Buzato (2007, p.159), a maneira como Soares (2002) conceitua e aborda o letramento digital é "congruente com a que têm utilizado diversos outros autores (Snyder, 1997; Kress, 2005; Bolter, 1993) preocupados em delinear 'rupturas' entre os letramentos tradicional e digital" e em avaliar as repercussões sociais dessas rupturas, em especial no contexto da educação. Para o pesquisador, em geral, estudos dessa vertente focalizam dois aspectos em que está centrada a análise de Soares (2002), quais sejam: a mudança no espaço de escrita, da página para a tela; e os novos mecanismos de produção, reprodução e difusão dos textos eletrônicos, denominados, genericamente, como tecnologias de hipertexto. Sobre esses aspectos, afirma Buzato (2007):

De forma bem sucinta pode-se dizer que, do ponto de vista do espaço da escrita, os estudos têm buscado caracterizar os LD [letramento digital] em função da utilização de diversos tipos de telas eletrônicas sobre as quais o texto e/ou imagens aparecem organizado(s) na forma de janelas que se alinham ou se sobrepõem espacialmente, ou se sucedem temporalmente. [...] Do ponto de vista dos mecanismos de produção, difusão e reprodução dos textos digitais, os autores simpáticos à tese da ruptura têm destacado o fato de que os tex- 
tos eletrônicos multilineares, ou hipertextos, produzidos, estocados e lidos em computadores e/ou redes telemáticas espacialmente distribuídas, enfraquecem o princípio da "autoria", isto é, que facultam ao leitor um papel muito mais ativo na construção dos percursos de leitura e, portanto das suas interpretações (BUZATO, 2007, p. 159-160).

Embora haja congruência entre alguns teóricos acerca do conceito de letramento digital, Buzato (2007) salienta que, pelo menos em português, o conceito tornou-se um termo guarda-chuva, que engloba muitos tipos de letramento, direta ou indiretamente relacionados às NTIC. Em outras palavras, o termo abarca uma variedade de discussões acadêmicas que, de modo geral, são oriundas de países anglófonos. Dessa forma, em inglês temos: digital literacy, eletronic literacy, computer literacy, media literacy, web literacy, cyberliteracy, hypermedia literacy, information literacy, electracy, multimodal literacy, visual literacy, numeracy e outros.

Ao realizar esse inventário de termos, Buzato (2007) expõe que a discussão dessas expressões pode assumir diferentes práticas com as NTIC e discursos divergentes sobre o termo letramento digital. Isso significa que não se trata apenas de uma questão de nomenclatura e, sim, de abordagens teóricas distintas sobre o conceito.

Uma dessas abordagens parte de uma visão determinista do letramento que, segundo Buzato (2007), levaram muitos autores (Goody, Olson e Greenfield) a proporem teorias de uma "Grande Divisão", segundo as quais a introdução da escrita teria provocado uma cisão entre os grupos humanos, causando nos grupos que dela dispunham desenvolvimentos tais como o pensamento lógico-dedutivo, o avanço da ciência, o surgimento da democracia, e condenando, por sua ausência, as sociedades ágrafas (e/ou grupos analfabetos) ao pensamento não-lógico, ao atraso científico-tecnológico e às formas "selvagens" de organização social (BUZATO, 2006, p.6).

Outra perspectiva apontada por Buzato (2007) orienta-se por uma visão neutralista/instrumental do letramento. Para essa concepção, os ensinos da leitura e da escrita devem estar focados no domínio e na mensuração de habilidades discretas (isto é, da escrita vista enquanto instrumento técnico). De acordo com Buzato (2007), essa perspectiva contribuiu para visões e práticas escolares que não fomentavam uma atitude crítica do leitor em relação áquilo que lia, nem preparavam o aluno para utilizar a escrita como veículo de sua própria voz social ou para utilizar a leitura e a escrita para problematizar sua própria situação social e construir formas de melhorá-la.

Knobel e Lankshear (2006), por sua vez, ao tratarem das tendências do conceito de letramento digital, apresentam outras duas. A primeira considera que o letramento estendeu a "habilidade de ler e escrever" para a "habilidade de compreender informação" (LANHAM, 1995 apud KNOBEL; LANKSHEAR, 2006. p. 12). Para Lanhan (1995) apud Knobel e Lankshear (2006), ser letrado digitalmente significa ser habilidoso em decifrar imagens complexas e sons, bem como as sutilezas sintáticas das palavras. Dito de outro modo, segundo Almeida (2013), significa ser capaz de localizar, organizar, compreender, avaliar e analisar informações usando a tecnologia digital.

Gilster (1997 apud KNOBEL; LANKSHEAR, 2006. p. 13) afirma que o letramento digital envolve quatro competências-chave: reunir conhecimento, avaliar informações, pesquisar, e navegar em rotas não-lineares (hipertextos). Para Knobel e Lankshear (2006), o conceito proposto por Gilster (1997) diz respeito a uma visão do letramento que se volta para a habilidade de ler, escrever e, além disso, lidar com informações utilizando as tecnologias e os formatos da atualidade (GILSTER, 1997 apud KNOBEL; LANKSHEAR, 2006. p.13).

Almeida (2013, p. 56), analisando as definições de Lanhan (1995) e Gister (1997), afirma que os conceitos propostos pelos pesquisadores levam em conta uma visão unitária do letramento, como algum tipo de "coisa", uma capacidade ou habilidade ou domínio de competências. Para ela, "esse modelo de letramento digital se refere às habilidades e às técnicas abstratas, $e$ os aprendizes são ensinados a codificar e a decodificar como preparação para a leitura e escrita em diversos contextos digitais".

A outra abordagem citada por Knobel e Lankshear (2006) entende que o termo "letramentos digi- 
tais", no plural, responde melhor ao novo cenário social e educacional, pois prioriza a enorme quantidade de práticas sociais que envolvem esse fenômeno, além de implicar uma mobilização de políticas vinculadas a uma perspectiva sociocultural do letramento. Partindo, então, desse ponto de vista, os pesquisadores propõem a pluralização do termo por entenderem que letramentos digitais representam uma variedade de práticas sociais e concepções de engajamento na elaboração de significados. Essa análise está centrada na forma como o letramento afeta o contexto em que está inserido ou os "[...] conjuntos de práticas sociais associadas a sistemas simbólicos particulares e as tecnologias a eles relacionadas" (BARTON, 1994).

A partir do prisma dessa última tendência apontada no parágrafo anterior, consideramos, neste texto, que os letramentos digitais ocorridos no curso LINTEC estão relacionados às práticas sociais e às inúmeras maneiras pelas quais os participantes da pesquisa se engajam na produção escrita ocorrida no Facebook, tomado como AVA. Nesse sentido, enfatizamos a adoção de uma perspectiva social tanto na abordagem dos letramentos acadêmicos, como na abordagem dos letramentos digitais. Ambos termos são utilizados no plural para indicar o entendimento de que os usos da escrita e das novas tecnologias dizem respeito ao fazer sentido, à identidade, ao poder, à autoridade e aos princípios de natureza institucional. Logo, não podem ser tratados como habilidades discretas e neutras.

A discussão das abordagens do ensino da escrita e das NTIC aponta elementos conceituais utilizados como referência na análise a ser apresentada a seguir. Dessa forma, o entendimento das diversas tendências no campo do letramento digital é fundamental para a compreensão das práticas de escrita no curso de especialização lato sensu, em estudo, visto que buscamos, neste artigo, refletir sobre o significados da escrita associada ao uso de NTIC no contexto da formação de professores. No próximo tópico, antes de adentramos, propriamente, no evento de letramento digital em análise, apresentaremos uma visão geral do Facebook.

\section{A Plataforma Virtual de Aprendizagem do curso LINTEC: O Facebook}

Das 12 disciplinas ocorridas no curso LINTEC, duas disciplinas ocorreram de modo virtual, quais sejam: Leitura, Escrita e Hipertexto e Novos Letramentos. O AVA utilizado pelos professores foi o Facebook - rede social gratuita que foi lançada em 2004. Conforme Allegretti (2012), o Facebook é um serviço que se insere no rol das mídias da Web 2.0, que se caracterizam pela liberação do polo de emissão, sendo também identificadas como "mídias de função pós-massiva".

Para participar do Facebook, os usuários devem se registrar antes de utilizar o site. Feito isso, podem criar um perfil pessoal, adicionar outros usuários como amigos e trocar mensagens. Ademais, os usuários podem participar de grupos de interesse comum. A seguir, apresentamos a página criada pelo professor para a disciplina Novos Letramentos no Facebook.

Figura 1- Página do Facebook da disciplina Novos Letramentos

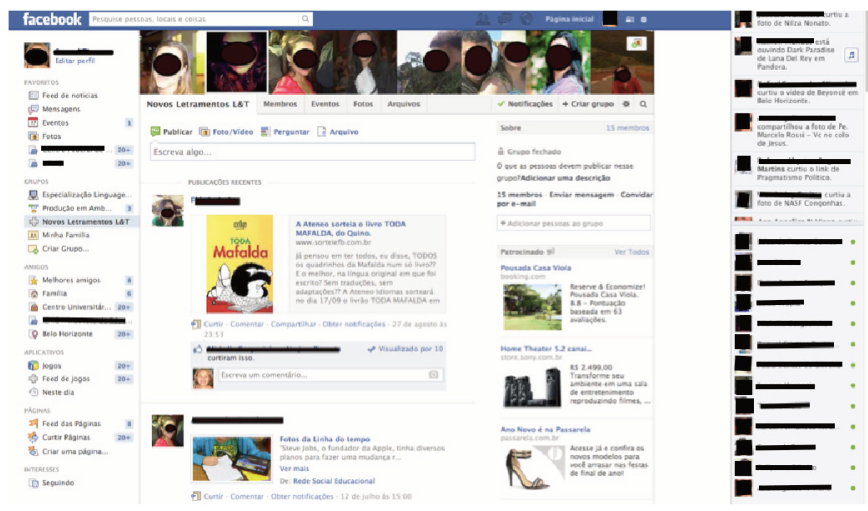

Fonte: Banco de dados da pesquisa, 2012.

Observando a Figura 1, verificamos que as imagens e o texto escrito misturam-se na página. As mensagens são organizadas lado a lado, na parte superior e inferior e entre as imagens, exigindo um tipo de leitura e escrita diferentes do convencional (GAL LARDO, 2013). Na tentativa de compreender o AVA adotado pelos professores, dividimos a figura acima em duas seções: barras horizontais e verticais. Na primeira seção, há duas barras. A primeira trata-se da imagem abaixo: Figura 2 - Barra horizontal 1 do Facebook 
Fonte: Banco de dados da pesquisa, 2012.

Na parte superior da página do Facebook, há uma barra azul, vista na Figura 2, acima, em que aparece o nome da rede social Facebook. Ao lado da palavra Facebook, há um campo de busca em que se pode procurar por pessoas, locais e diferentes assuntos/ temas na rede social. Ao lado desse campo de pesquisa, há ícones sombreados. O primeiro funciona para solicitar ou aceitar amizades na rede. O segundo possibilita a interlocução entre as amizades por meio de um chat. O terceiro informa as notificações recebidas na página do Facebook. Após os itens sombreados, há um link denominado página inicial que leva à página inicial do Facebook, neste caso, de uma das autoras desse texto. Em seguida, vem a foto de uma das autoras deste artigo, pois, para acompanhamento das aulas virtuais, a pesquisadora pediu autorização aos professores para participar do grupo fechado no Facebook denominado Novos Letramentos L\&T. Por isso, todas as informações da Figura 1 relacionam-se ao seu perfil no Facebook. Ao lado da foto há um cadeado que demonstra que essa página se trata de um grupo fechado. À direita do cadeado, uma pequena engrenagem indica acesso à ferramenta que tem as funções de criar página, configurar página, solicitar ajuda, entre outros. Na segunda barra vista, na Figura 3, abaixo, destacamos as fotos dos membros do grupo. Salientamos que cobrimos com um disco negro os rostos dos participantes da pesquisa para preservar suas identidades.

Figura 3 - Barra horizontal 2 do Facebook

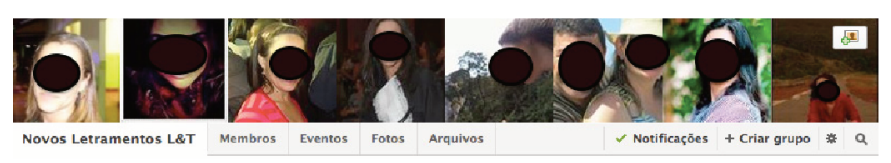

Fonte: Banco de dados da pesquisa, 2012.

Além das fotos, há o nome do grupo Novos Letramentos L\&T e as abas membros, eventos, fotos e arquivos. Há, também, notificações e, novamente, a possibilidade de criar grupos, configurar e pesquisar no Facebook. Com relação às barras verticais, foram divi- didas em quatro subseções, como mostramos na Figura 4, abaixo:

Figura 4- Barras verticais do Facebook

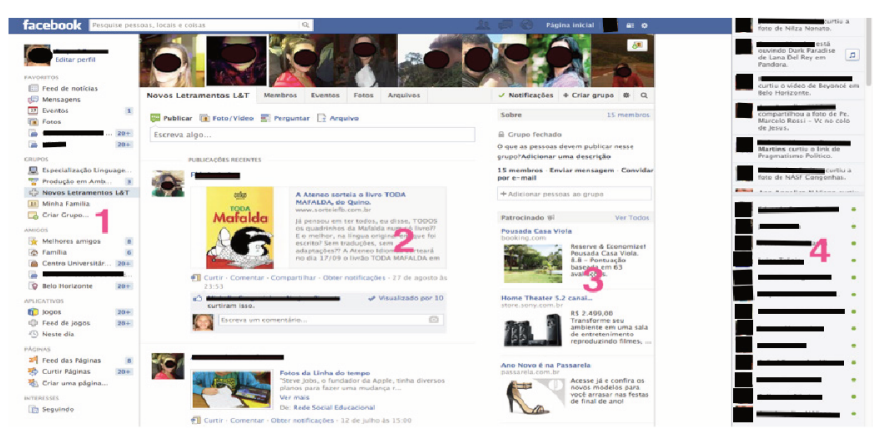

Fonte: Banco de dados da pesquisa, 2012.

A primeira coluna (número 1) indica caminhos para outros modos de interação (mensagens privadas, por exemplo), conteúdo do site (dicas, interesses, aplicativos) e grupos de amigos. A segunda coluna (número 2) traz um quadro na parte superior, para que o usuário escreva algo, no feed de notícias, em seu status, e/ou coloque fotos ou vídeos e/ou proponha questões e/ ou anexe um documento. Abaixo desse quadro, há uma coluna denominada feed de notícias, que apresenta as postagens dos amigos e oferece caminhos que incentivam a interação por meio das opções curtir, comentar e compartilhar aquilo que foi postado. Na parte superior da terceira coluna (número 3), há a opção de criar eventos e participar de jogos e outras atividades para as quais o dono do perfilé convidado. Abaixo, nessa mesma coluna, há propagandas com links dos patrocinadores do Facebook. Finalmente, a quarta coluna (número 4) mostra as atividades dos amigos em tempo real, ou seja, as postagens, comentários e a opção curtir, que estão acontecendo no momento da visualização. $\mathrm{Na}$ parte inferior dessa coluna, há, também, a opção para o usuário declarar seu status online ou bloquear essa informação. Caso não haja o bloqueio, todos amigos online do Facebook podem interagir sincronicamente na página, através da função bate-papo.

Por meio dessa descrição, questionamo-nos sobre o papel atribuído ao Facebook enquanto AVA acadêmico. É notório que o Facebook apresenta várias ferramentas de interação que propiciam a comunicação entre 
professores e alunos do curso. A rede social permite o compartilhamento de praticamente todo tipo de conteúdos digitais (imagens, vídeos, áudios, simulações etc.). Oferece, também, diversas ferramentas para a comunicação entre os seus usuários (chats, fóruns, envio de mensagens etc.), além de facilitar a criação e o compartilhamento de conteúdos, como, por exemplo, blogs, links, vídeos etc. Além disso, propicia aos produtores e leitores dos textos o potencial de significação dos modos ou meios semióticos (KRESS, 2010), pois, conforme Dionísio (2011), com o advento das novas tecnologias, [entendendo aqui o Facebook, enquanto uma NTIC] se criam novas imagens, novos layouts (...). Todos os recursos utilizados na construção dos gêneros textuais exercem uma função retórica na construção de sentido dos textos. Cada vez mais se observa a combinação de material visual com a escrita; vivemos, sem dúvida, numa sociedade cada vez mais visual. Representação e imagens não são meramente formas de expressão para divulgação de informações, ou representações naturais, mas são, acima de tudo, textos especialmente construídos que revelam as nossas relações com a sociedade e com o que a sociedade representa (DIONÍSIO, 2011, p.138).

Pelo exposto, são evidentes as potencialidades do Facebook enquanto AVA. Allegretti et al (2012), discutindo esses potenciais, apontam que essa rede social tem sido utilizada como espaço de aprendizagem em diferentes contextos de formação "por facilitar a convergência e o compartilhamento de materiais de diferentes mídias". Segundo a autora, o Facebook apresenta algumas vantagens que podem favorecer o seu uso educacional, a saber: facilidade de conversação, auxílio na diminuição das relações hierárquicas de poder entre professor e alunos, melhora do nível de relacionamento, suporte à interação entre alunos, rompendo com o discurso limitado tipo aluno-professor; possibilidade de substituir sistemas de gerenciamento de aprendizagem (Learning Management System) formais como o Moodle e Blackboard, entre outros. Além dessas características comunicacionais e de interatividade, temos a possibilidade de pensar numa aprendizagem com currículo flexível, transgredir o tempo e espaço formal, bem como oferecer novas formas de tratar o conhecimento no âmbito escolar (ALLEGRET-
TI et al, 2012, p.54). Valadares e Murta (2012, p.1), na mesma direção de Allegretti et al (2012), compreendem que as redes sociais de relacionamento, como Facebook, MySpace, Twitter, YouTube, ocupam lugar de destaque na sociedade contemporânea e têm sido usadas como recursos pedagógicos. Esses autores veem as "redes sociais como um ambiente potencialmente livre e aberto para (re) apropriações que, na relação com os usuários, transcendem o sentido que tinham a priori".

Se, por um lado, devemos reconhecer as potencialidades do Facebook com AVA, conforme foi indicado por diversos autores, por outro lado, interessa-nos saber de que forma essas potencialidades são exploradas localmente por grupos sociais diversos e as implicações dessas explorações para o que se pode aprender sobre a escrita em um contexto digital. Ademais de se pensar acerca das potencialidades do Facebook enquanto AVA, entendemos a necessidade de se deslocar o foco dado à aquisição de habilidades (modos e canais) para se concentrar no sentido de pensar o letramento e usos das tecnologias como práticas sociais. Se compreendermos o letramento como um modo ou um canal, "cairemos na armadilha de reificá-lo de acordo com a forma, deixando de levar em conta práticas sociais ligadas à construção, aos usos e aos significados do letramento no contexto" (STREET, 2012a, p.74). Ao nosso ver, a postulação feita por Street sobre o risco de adotarmos uma visão reduzida do letramento se aplica também à adoção de uma visão neutra e descontextualizada das NTIC. Isso implica, então, o desafio de reconhecer e compreender os múltiplos letramentos configurados a partir de usos diferenciados, construídos localmente por participantes de diferentes grupos sociais, que variam no tempo, no espaço e nas relações de poder. No próximo tópico, sob a luz das teorias apresentadas, discutimos as práticas de escrita, propriamente dita, ocorridas principalmente, no feed de notícias do Facebook da disciplina Novos Letramentos L\&T.

\section{Práticas de letramento acadêmico nas aulas virtuais do curso LINTEC}

A partir do objetivo geral deste artigo, qual seja, compreender os significados da escrita associada ao 
uso de NTIC no contexto da formação de professores, questionamo-nos: Quais as práticas de escrita construídas no Facebook enquanto AVA? O que participantes da pesquisa escreveram? Com que propósito? Quais os gêneros textuais solicitados aos alunos? Com o intuito de responder a essas perguntas, elaboramos os quadros 01 e 02, abaixo, com o objetivo de identificar os gêneros textuais produzidos nas disciplinas que ocorreram virtualmente. Os quadros estão organizados da seguinte forma: data, gêneros textuais e produtores de texto, respectivamente. Para cada quadro, fizemos gráficos para visualizar a recorrência com que cada gênero textual foi solicitado pelos professores aos seus alunos e levamos em consideração as postagens principais realizadas no feed de notícias.

Quadro 01 - Gêneros textuais da disciplina Novos Letramentos

\begin{tabular}{l|l|l}
\hline Data & Gêneros textuais & $\begin{array}{l}\text { Produtores de } \\
\text { Texto }\end{array}$ \\
\hline $29 / 09 / 2012$ & Aviso & Professora \\
\hline $30 / 09 / 2012$ & Aviso & Professora \\
\hline $04 / 10 / 2012$ & Atividade & Professora \\
\hline $07 / 10 / 2012$ & Carta/ solicitação & Aluno \\
\hline $08 / 10 / 2012$ & Aviso/ Comunicado & Professora \\
\hline $10 / 10 / 2012$ & Comentários & Aluno \\
\hline $11 / 10 / 2012$ & $\begin{array}{l}\text { Aviso } \\
\text { Comentário }\end{array}$ & $\begin{array}{l}\text { Professora } \\
\text { Aluno }\end{array}$ \\
\hline $12 / 10 / 2012$ & Aviso & Professora \\
\hline $13 / 10 / 2012$ & Comentários & Aluno \\
& Aviso & Professora \\
\hline $14 / 10 / 2012$ & Comentário & Aluno \\
\hline $15 / 10 / 2012$ & Comentário & Aluno \\
\hline $16 / 10 / 2012$ & Aviso & Professora \\
& Comentário & Aluno \\
\hline $17 / 10 / 2012$ & Comentário & Aluno \\
\hline $18 / 10 / 2012$ & Comentário & Aluno \\
\hline & &
\end{tabular}

Fonte: Elaboração própria, 2015.
Gráfico 1- Gêneros textuais da disciplina Novos Letramentos

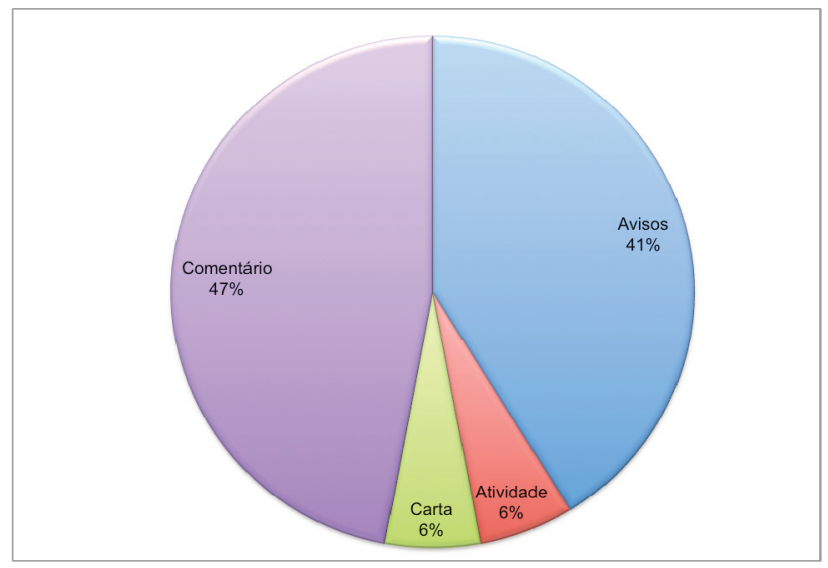

Fonte: Elaboração própria, 2015.

Da mesma forma que fizemos em relação à disciplina Novos Letramentos, construímos o Quadro 2 e o Gráfico 2 para identificarmos os gêneros textuais produzidos pelos participantes da pesquisa na disciplina Produção em Ambientes Virtuais.

Quadro 02 - Gêneros textuais da disciplina Produção em Ambientes Virtuais

\begin{tabular}{l|l|l}
\hline Data & Gêneros textuais & Participantes \\
\hline $02 / 09 / 2013$ & $\begin{array}{l}\text { Aviso } \\
\text { Plano de Ensino } \\
\text { Autoapresentação }\end{array}$ & $\begin{array}{l}\text { Professora } \\
\text { Alunos }\end{array}$ \\
\hline $03 / 09 / 2013$ & Autoapresentação & Aluna \\
\hline $04 / 09 / 2013$ & Autoapresentação & Aluna \\
\hline $05 / 09 / 2013$ & Aviso & Professora \\
\hline $06 / 09 / 2013$ & Aviso & Professora \\
\hline $07 / 09 / 2013$ & Aviso & Professor \\
\hline $08 / 09 / 2013$ & Aviso & Professora \\
\hline $09 / 09 / 2013$ & Aviso & Professora \\
\hline $10 / 09 / 2013$ & Aviso & Professora \\
\hline
\end{tabular}

Fonte: Elaboração própria, 2015. 
Gráfico 2- Gêneros textuais da disciplina Produções em Ambientes Digitais

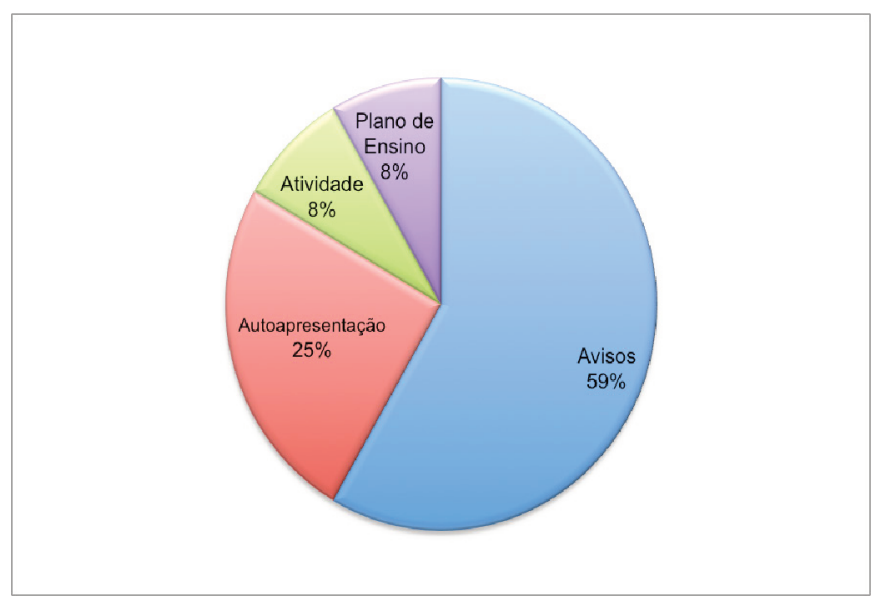

Fonte: Elaboração própria, 2015.

Contrastando os Quadros 01 e 02 e os Gráficos 01 e 02 , observamos que os alunos e os professores, no feed de notícias, postaram avisos, plano de ensino, autoapresentações, exercícios e comentários. Na disciplina Novos Letramentos, notamos que os gêneros textuais mais produzidos foram avisos (41\%) e comentários (47\%). Os avisos realizados pela professora são de naturezas diversas. De modo geral, tratavam da organização da disciplina, do AVA e dos pedidos de esclarecimento dos alunos quanto à realização da primeira atividade. Uma possível explicação para a predominância dos avisos relaciona-se à própria natureza do Facebook, que prima pela agilidade e rapidez das informações. Já os comentários relacionavam-se à primeira atividade da disciplina, em que a professora solicitou aos alunos que discutissem o conceito de letramento no feed de notícias do Facebook a partir do texto de Soares (2002). Salientamos, que neste artigo, e, pela própria extensão do mesmo, não nos focalizaremos nos comentários feitos pelos participantes da pesquisa.

Com relação à disciplina Produção em Ambientes Virtuais, percebemos que os avisos ocuparam a maior parte das postagens, com 59\%. A autoapresentação ocupou o segundo lugar, com $25 \%$, o exercício e o plano de ensino ocuparam o terceiro lugar, com $8 \%$ cada. Os avisos, na disciplina Produção em Ambientes Virtuais, cumpriram o mesmo papel da disciplina Novos Letramentos: informar os alunos sobre a organização da disciplina e orientar a atividade 1 , que tratou da discussão do termo comunicação. Nas autoapresentações, tanto os alunos como os professores se apresentaram no AVA. Cumpre dizer que em Produções em Ambientes Virtuais, ao contrário do que ocorreu em Novos Letramentos, não houve comentários sobre o texto indicado para leitura pelo professor no feed de notícias do Facebook, e isso é significativo, pois não existiu uma discussão prévia dos textos que poderiam auxiliar na produção escrita dos alunos.

Por meio desse levantamento, percebemos que no AVA os alunos e os professores do curso LINTEC produziram, predominantemente, gêneros textuais que são denominados por Dionísio e Fischer (2010) ferramentas pedagógicas (aviso, autoapresentações, plano de ensino, atividade, comentários). O que nos chama atenção, no entanto, diz respeito a ausência dos chamados gêneros científicos (DIONÍSIO E FISCHER, 2010), ao longo das aulas analisadas, uma vez que o contexto em destaque é um curso de especialização lato sensu e, logo, acadêmico.

Outro aspecto que queremos salientar são os gêneros textuais produzidos pelos alunos e que foram solicitados pelos docentes para serem entregues in box no Facebook. Na Figura 5, a seguir, apresentamos as solicitações realizadas pelos docentes das duas disciplinas:

Figura 5 - Trabalho final da disciplina Produção em Ambientes Digitais

\section{Trabalho final}

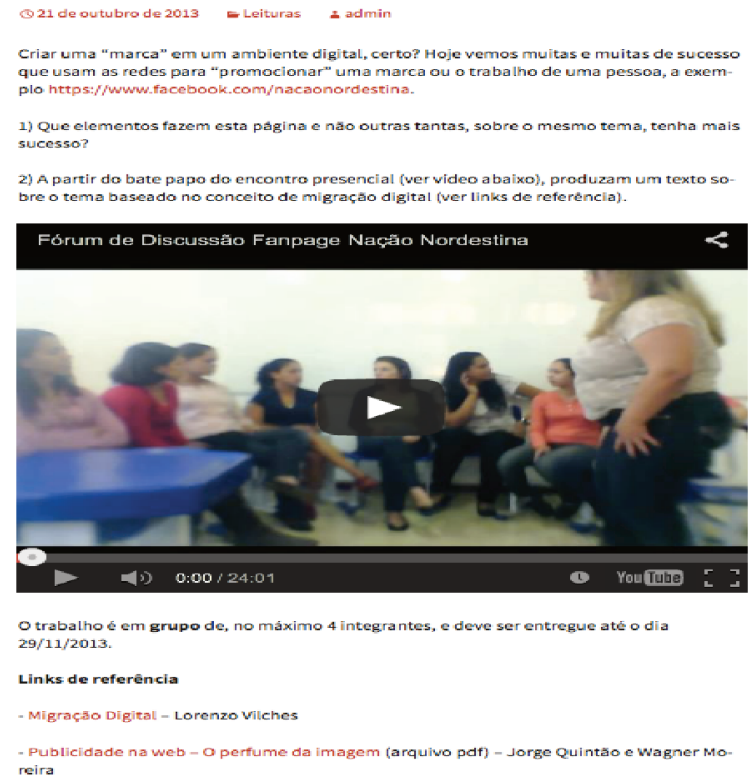

reira

Fonte: Banco de dados da pesquisa, 2012. 
$\mathrm{Na}$ figura anterior, um dos professores da disciplina Produções em Ambientes Digitais solicitou aos alunos que produzissem um "texto" sobre o tema migração digital. Tal solicitação explora diferentes recursos das NTIC (apresentação de link para outra página do Facebook, gravação em vídeo de discussão presencial sobre o tema proposto e indicação de "links de referência" textos disponíveis na WEB sobre a temática abordada). Tais recursos configuram-se como uma exploração local das potencialidades do Facebook como AVA que, nesse caso, parecem contribuir para a composição de um referencial teórico que será, provavelmente, explorado na produção do texto escrito.

É interessante notar que a proposição da atividade (figura 5) apresenta expressões que a recobrem de informalidade (por exemplo, a pergunta inicial, "Criar uma 'marca' no ambiente digital, certo?"). Além disso, observamos a vinculação de fenômenos linguísticos comumente observados entre usuários das NTIC (por exemplo, o neologismo "promocionar" uma marca) e entre professores e alunos de outros níveis de ensino (por exemplo, assertividade em definir certas condições para a produção, "produzam um texto", "é em grupo", "deve ser"). Tais características contribuem para a composição híbrida do texto produzido pelo professor, apresentando, assim, traços de gêneros textuais presentes no Facebook e traços de gêneros textuais de natureza escolar.

Com relação às orientações dadas pelo professor, cumpre informar que, embora, o docente explore vários recursos das NTIC e indique alguns aspectos relativos às condições de produção textual (por exemplo, escrever em grupo de quatro pessoas), verificamos que outros aspectos dessa produção permanecem implícitos ou não são abordados. Ao pedir aos alunos que produzam um texto, o professor deixou vago o gênero textual que pretendia que os discentes escrevessem e quais seriam os seus potenciais leitores. Dessa forma, tanto os alunos, (como nós analistas), podemos assumir que se os alunos redigissem uma resenha, um relatório ou qualquer outro gênero textual; não haveria diferença, uma vez que o docente não explicitou o gênero que os alunos deveriam escrever. Ademais, percebemos que a proposição da atividade pode, de certa maneira, gerar dúvidas quanto à temática a ser contemplada.
Uma das prováveis explicações para que o professor tenha solicitado aos alunos que, simplesmente, produzissem um "texto" deve-se ao fato de que todos os alunos do curso LINTEC já fizeram um curso superior e/ou já realizaram uma disciplina denominada Prática de Redação Científica que ocorreu, no curso, presencialmente. Daí se pressupõe que os discentes já conhecem os textos acadêmicos. Importa-nos destacar que tal perspectiva ancora-se na prática do mistério (LILLIS, 1999), que pouco considera as histórias prévias de letramento dos alunos, as habilidades de leitura e escrita desenvolvidas em formações anteriores e as habilidades a serem desenvolvidas no domínio acadêmico. Vimos, então, que as convenções de escrita que os alunos deveriam usar na produção do "texto" sobre migração digital permanecem implícitas, em vez de explícitas, porque parece que o professor parte do pressuposto de que os estudantes já sabem que "texto" é esse (LILLIS, 1999).

Outra solicitação realizada para que os alunos postassem in box no Facebook foi a de Novos Letramentos, como expomos, abaixo:

Figura 6- Tarefa 2 da disciplina Novos Letramentos

TAREFA 2

Olá, pessoal,

acompanhei a discussão de vocês e acho que estamos no caminho mais certa possivel. Nada de transmissōes. A ideia é que uma provocaçāo possa gerar leituras e discussōes entre as próprias pessoas interessadas. É necessario que haja esse engajamento para que a aprendizagem se de. Álém disso, todos vôs jé têm algum nivel de lo Além disso, quital, mas aqu estamos nos envolvendo com outros letramentos.

Bem, agora que todos leram, discutiram, debateram, etc., vamos partir para uma sistematização. Avaliarei a participaçāo de todos neste debate, mas agora farei uma avaliaçāo mais individualizada, além de ter condiçōes de dar feedback a cada um.

Lá vai:

REDIJA, individualmente, um texto DISSERTATIVO com o seguinte tema: alfabetizaçāo e letramento, questōes. Isso NÃo É o título. É apenas a ideia. Pensem aí em cerca de 3 páginas (nem muito mais nem muito menos). ABNT direitinho, Times 12 , espaçamento, 1,5 , com referências bibliográficas, tá? Prazo bombástico: dia 27 de outubro, ok?

Pessoal, até lá, liberarei aqui alguma coisa para vocês lerem e debaterem novamente. O texto nāo estará sozinho. Fiquem atentos.

ATENÇÃO: o envio do texto finalizado deve ser feito pelas mensagens inbox aqui do Facebook, tá? Năo enviem por email nem por outro canal. abraços

Curtir : Comentar

Fonte: Banco de dados da pesquisa, 2012.

Ao comparar as proposiçôes referentes ao Trabalho final da disciplina Produção em Ambientes Digitais à Tarefa 2 da disciplina Novos Letramentos, apresen- 
tadas, respectivamente, nas Figuras 5 e 6, notamos algumas semelhanças. Pode-se ver na Figura 6, por exemplo, a natureza híbrida da escrita que ora apresenta traços de gêneros textuais presentes no Facebook e ora traços de gêneros textuais de natureza escolar. Nas palavras destacadas a seguir, evidenciamos essa hibridização: "in box aqui no Facebook, tá", "dia 27 de outubro, ok", "lá vai", "alguma coisa", "um texto dissertativo", “espaçamento 1,5 ", "avaliarei a participação de todos no debate" e outras.

Outras semelhanças relativas às questões pertinentes à explicitação ou não das condições de produção textual também podem ser observadas nas orientações apresentadas na Figura 6, visto que a professora pediu aos alunos que redigissem um texto dissertativo com o seguinte tema: "alfabetização e letramento, questões". Analisando essa proposta, entendemos que seria mais adequado, à luz dos estudos linguísticos atuais sobre os gêneros discursivos (MARCUSCHI, 2002; BAKHTIN, 2011), solicitar a produção de um gênero discursivo específico e não um tipo textual, pois tal solicitação poderia favorecer reflexões sobre aspectos constitutivos da situação comunicativa em que o texto estaria inserido, como, por exemplo, seus potenciais leitores, meio de circulação, função social etc.

Notamos que as orientações dadas à Tarefa 2 pela professora com relação à produção de texto referiramse, tão somente, aos aspectos normativos da ABNT e, dessa forma, percebemos, tal como ocorreu na disciplina Produção em Ambientes Digitais (conforme apresentado na Figura 5), o predomínio das "práticas institucionais do mistério" (LILLIS, 2009). Assim, aspectos como condições de produção e elementos linguístico-discursivos que materializam o referido "texto dissertativo" foram deixados de lado. Em outras palavras, não basta explicar como o texto se estrutura linguisticamente; é necessário ficar explícito os motivos pelos quais algumas práticas são privilegiadas no meio acadêmico em detrimento de outras, o que significa justificar e argumentar de acordo com as convenções escriturais da academia e para que e para quem se escreve no contexto acadêmico.

Com relação às últimas duas questões acima - para que e para quem se escreve -, observamos, analisando as notas de campo e os vídeos realizados na pesquisa, que a professora foi a única leitora dos textos produzidos e colocados in box pelos alunos e o seu objetivo era, simplesmente, avaliar os discentes. Dessa forma, há a negação do caráter interacional da escrita, ou seja, uma desapropriação do sujeito da linguagem (LEAL, 2000).

Salientamos, ainda, nas orientações dadas pela professora, vistas na Figura 6, a seguinte afirmativa: "todos vocês já têm algum nível de letramento digital". Ao dizer isso, a docente deixa transparecer que compartilha de uma visão relacionada aos aspectos mecânicos da tecnologia computacional que trazem, subjacente, uma noção de letramento digital como um conjunto de habilidades básicas e funcionais para o uso do computador. Em outras palavras, uma visão autônoma do letramento (STREET, 1984), focada no determinismo do canal ou da tecnologia e não nas práticas sociais que, na visão de Street (2012, p. 74), "atribuem significados e conduzem a efeitos e não o canal em si". Lankshear; Snyder; Green (2000), na mesma direção de Street (1984), concebem que uma visão de letramento digital com foco nos aspectos meramente tecnológicos restringe a compreensão da dimensão social e cultural que as tecnologias engendram, tornando-se necessária a ampliação das análises a respeito das atividades de linguagem que por ela é mediada.

Concluindo essa seção, é interessante destacar nas orientações dadas pelos professores das disciplinas Produção em Ambientes Digitais e Novos Letramentos uma perspectiva escolarizada de ensino que foca no controle, visto que os alunos seriam avaliados nesse processo. Além disso, há imposição e inflexibilidade comunicativa, uma vez que os discentes tiveram poucas oportunidades de refletir, de maneira explícita, durante as disciplinas sobre as características e funções dos chamados "texto" e "texto DISSERTATIVO". A falta de discussão sobre esses aspectos, aliada ao não endereçamento das dúvidas dos alunos, parece sugerir um entendimento por parte dos professores de que a produção dos textos solicitados seria de natureza 'transparente', ou seja, já conhecida e dominada pelos cursistas, dispensando, portanto, explicações.

Ademais, devemos destacar que a imposição e a inflexibilidade comunicativa no tratamento da produção 
textual no contexto observado correspondem a uma exploração bastante pobre das potencialidades tecnológicas do Facebook como AVA. De um lado, o professor explora diferentes mídias para se comunicar com múltiplos leitores (apresentação de tarefas que incluem vídeos e links em suas proposições aos alunos, por exemplo); do outro lado, os alunos foram, tão somente, posicionados como usuários desses recursos, visto que não lhes foi solicitado que explorassem as potencialidades do Facebook para a produção, por exemplo, de gêneros textuais digitais. Daí, se conclui que os recursos multimidiáticos, por exemplo, foram utilizados para subsidiar uma produção escrita destinada a um único leitor, de circulação e de endereçamento limitados e para fins avaliativos.

\section{Considerações Finais}

Como indicamos na abertura deste texto, políticas públicas e programas educacionais visam promover a disseminação e o uso das novas tecnologias como recurso de ensino. Porém, se faz necessário investigar como tais processos vêm ocorrendo para que possamos aprimorar o desenvolvimento de iniciativas que colaborem mais efetivamente para a formação de profissionais da educação capazes de articular NTIC aos processos de ensino e aprendizagem de maneira mais signifcativa. Neste texto, a partir da adoção da abordagem social dos letramentos acadêmicos e dos letramentos digitais, analisamos as condições em que alunos de um curso de pósgraduação lato sensu têm oportunidades de produzir textos escritos no contexto digital, no caso analisado, em disciplinas que utilizam o Facebook como AVA, em curso de especialização em Linguagem e Tecnologia. Ao realizar tal análise, visamos examinar as condições em que vêm se dando a articulação entre práticas de ensino da escrita acadêmica associadas à aprendizagem de usos das NTIC em contextos de ensino.

Inicialmente, apresentamos uma visão panorâmica dos processos de ensino que demandaram dos alunos a produção de textos escritos nas aulas virtuais ocorridas no curso LINTEC, um curso de especialização voltado para profissionais de diversas áreas. Essa visão panorâmica permitiu-nos ver que os alunos produziram um rol variado de gêneros textuais. Verificamos que avisos e comentários são os mais recorrentes. Observamos que os gêneros textuais produzidos nas aulas virtuais foram utilizados tipicamente como ferramentas pedagógicas (DIONÍSIO E FISCHER, 2010) e focavam na administração da disciplina. Destacamos, ainda, que a escrita nesse contexto caracteriza-se como híbrida, apresentando traços de gêneros textuais presentes no Facebook e traços de gêneros textuais de natureza escolar.

Além dos gêneros textuais citados anteriormente, os alunos produziram textos que foram solicitados pelos docentes para serem postados in box no Facebook. Analisando essas propostas, percebemos que os docentes, ao orientarem os alunos do curso LINTEC para a produção escrita, não apresentaram explicações do texto solicitado e nem explicitaram como os discentes deveriam proceder para a realização do trabalho escrito. Os professores privilegiaram aspectos superficiais do "texto" e do "texto dissertativo". Em decorrência disso, pode-se inferir que os significados da escrita nesse contexto decorrem de uma visão autônoma do letramento em que as condições de produção da escrita estavam orientadas por um modelo de letramento que privilegia a abordagem de características estruturais e superficiais do texto, implicando uma visão na qual basta ter domínio dessas características e desenvolver habilidades de reconhecê-las e produzi-las, para que alguém, no caso os alunos do curso LINTEC, seja capaz de usar tais habilidades em outras situações e contextos. Assim, a ausência de discussão e de reflexão sobre outros aspectos que impõem restrições aos processos de produção textual no contexto observado, como por exemplo, pressões de tempo, uso da escrita com objetivos avaliativos, descontextualização da produção textual, reforçam uma visão autonôma da escrita no contexto de ensino analisado. Dessa forma, a abordagem de ensino adotada pelos professores parece corresponder ao que foi denominado de modelo de habilidades, que favorece a instituição da prática institucional do mistério (LILLIS, 1999).

No que concerne à exploração da NTIC, identificamos que os docentes exploraram várias potencialidades do Facebook como AVA (uso de vídeos, links etc.). Contudo, essa reapropriação ocorreu para con- 
formar uma perspetiva autônoma da escrita, ou seja, uma visão unitária do letramento, uma capacidade ou habilidade ou domínio de competências (KNOBEL; LANKSHEAR, 2006).

Tendo em vista as análises apresentadas anteriormente, entendemos que os professores e coordenadores de cursos de especialização lato sensu, ao planejarem e/ou organizarem cursos dessa natureza devem discutir e desenvolver estratégias mais eficazes que promovam o desenvolvimento de alternativas de ensino que favoreçam a compreensão da natureza social da escrita articulada às NTIC. O foco, então, da organização curricular deve centrar-se numa abordagem de ensino que leve em conta as funções sociais da escrita, ademais de se questionar como e para que ela é utilizada e suas implicações para o estabelecimento de relações de poder, construções identitárias e concepções relacionadas ao seu ensino no contexto universitário.

\section{Referências}

ALLEGRETTI, S. Aprendizagem nas redes sociais virtuais: o potencial da conectividade em dois cenários. Revista Contemporaneidade Educação e Tecnologia, São Paulo, v. 1, n. 2, p. 53-60, Abr. 2012. Disponível em: $<$ https://revistacontemporaneidadeeducacaoetecnolo gia02.files.wordpress.com/2012/04/pucsp_2012.pdf >. Acesso em: 01 abr. 2015.

ALMEIDA, E. Aprendizagem Situada e Letramentos Digitais no Estágio Supervisionado de Espanhol. 2013.226f. Tese (Doutorado em Linguística) - PósGraduação em Estudos Linguísticos, Universidade Federal de Minas Gerais, Belo Horizonte, 2013.

BARRETO, Raquel Goulart et al . As tecnologias da informação e da comunicação na formação de professores. Rev. Bras. Educ., Rio de Janeiro, v. 11, n. 31, p. 31-42, Apr. 2006. Disponível em: <http://www. scielo.br/scielo.php?script $=$ sci_arttext $\&$ pid $=$ S1413$24782006000100004 \& \operatorname{lng}=\mathrm{en} \& \mathrm{nrm}=\mathrm{iso}>$. Acessado em 08 julho de 2016.

BAKHTIN, M. Estética da criação verbal. São Paulo: Martins Fontes, 2011.

BARTON, D. Literacy: an Introduction to the Ecology of Written Language. London: Blackwell, 1994.

BRASIL. Lei n. 10.172, de 09 de janeiro de 2001. Aprova o Plano Nacional de Educação (PNE). Diário Oficial da União [da] República Federativa do Brasil, Brasília, DF, 10 jan. 2001.
BUZATO, M. Letramentos digitais e formação de professores. In: CONGRESSO IBERO-AMERICANO EDUCAREDE, 3., 2006, São Paulo. Anais. São Paulo: CENPEC, 2006. p. 1-7.

Entre a fronteira e a periferia: linguagem e letramento na inclusão

digital. 2007. 284 f. Tese (Doutorado em Linguística Aplicada) - Instituto de Estudos da Linguagem , Universidade Estadual de Campinas, Campinas, 2007. Disponível em: <http://libdigi.unicamp.br/ document $/$ ?code $=$ vtls000415042>.

Acesso em: 26 mai. 2015.

CERUTTI-RIZZATTI, M. E.; DAGA, A. C. O ato de ler e a formação docente na EaD. Revista Letrônica, v. 3, n. 2, p. 153-166, dez. 2010.

DIONÍSIO, M. L. Gêneros textuais e multimodalidade. In: KARWOSKI, A. GAYDECZKA, B. BRITO, K. (org.). Gêneros textuais: reflexões e ensino. São Paulo: Parábola Editorial, 2011.

L. FISCHER, A. Literacia(s) no Ensino Superior: Configurações em Práticas de Investigação. In: CONGRESSO IBÉRICO ENSINO SUPERIOR EM MUDANÇA: TENSÕES E POSSIBILIDADES, 2010, Braga. [Actas]. Braga: Universidade do Minho. CIED, 2010. p. 289-300.

FAIRCLOUGH, N. Discourse and social change.UK: Polity Press and Blackwell Publishers Ltd.,1992.

FIAD, R. A escrita na universidade. Revista da ABRALIN, v. Eletrônico, n. Especial, parte 2, 2011.

FRANCO, R. Práticas de Escrita em um Contexto de Formação Continuada: um estudo etnográfico do curso de especialização Linguagem e Tecnologia. 2015, 229f. Tese (Doutorado em Educação Tecnológica) - Programa de Pós-Graduação em Educação, Universidade Federal de Minas Gerais, Belo Horizonte, 2015.

GALLARDO, B. Comunicação transnacional no Facebook: uma análise discursiva das identidades digitais de professores de língua. 2013. 220f. Tese (Doutorado em Linguística) - Instituto de Estudos da Linguagem, Universidade Estadual de Campinas, Campinas, 2013.

GEE, J. P. Social linguistics and literacies: ideology in Discourses. 2ed. London/ Philadelphia: The Farmer Press, 1996.

GREEN, Judith; BLOOME, David. Ethnography and ethnographers of and in education: a situated perspective. In FLOOD, J; HEATH, Shirley; Lapp, D. (Ed.). Handbook of research on teaching literacy through the communicative and visual arts. New York: Simon \& Schuster Macmillan, p. 181-202, 1997. 
KNOBEL, M; LANKSHEAR, C. Digital literacy and digital Literacies: policy, pedagogy and research considerations for education. Digital Kompetanse, vol. 1, p. 12-24, 2006.

KRESS, G. Multimodality: a social semiotic approach to contemporary communication. London: Routledge, 2010 .

IVANIC, R. Writing and Identity: The discoursal construction of identity in academic writing. New York: Benjamins, 1998.

LANKSHEAR, Colin; SNYDER, Ilana; GREEN, Bill. Teachers and techno literacy: managing literacy technology and learning school. Australia: Allen \& Unwin, 2000.

LEA, M. R.; STREET, B. V. Student writing in higher education: an academic literacies approach. In: Studies in Higher Education, Abingdon, Oxon, UK, v. 23, n. 2, p. 157-172, 1998.

LEAL, L. Trajetória Escolar, Texto Escrito e Classe Social - um estudo longitudinal. 1999. 313f. Tese (Doutorado em Educação) - Pós-Graduação em Educação, Universidade Federal de Minas Gerais, Belo Horizonte, 1999.

LILLIS, T. "Whose Common Sense"? Essayist literacy and the institutional practice of mystery. In: JONES, C.; TURNER, J.; STREET, B. (orgs.). Students writing in the university: cultural and epistemological issues. Amsterdam: John Benjamins, p. 127-140, 1999.

LILLIS, T.; SCOTT, M. Defining academic literacies research: issues of epistemology, ideology and strategy. Journal of Applied Linguistics. vol 4.1, 2007, p.5-32. Disponível em: http://www.equinoxpub.com/JAL/ article/viewArticle/4563. Acesso em 01 jun. 2012.

MARCUSCHI, L. A. Gêneros textuais emergentes no contexto da tecnologia digital. In: REUNIÃO DO GEL - GRUPO DE ESTUDOS LINGUÍSTICOS DO ESTADO DE SÃO PAULO, 50., 2002. São Paulo, [Anais]. São Paulo, mai. 2002.

MITCHEL, J. C. Case studies. In: ELLEN, R. F. Ethnographic research: a guide to general conduct. London, FL: Academic Press Inc., 1984. p. 237-241.

PAIVA, V. L. M . O. A formação do professor para uso da tecnologia. In: SILVA, K.. A.; DANIEL, F. G.; KANEKO-MARQUES, S. M.; SALOMÃO, A. C. B. (Orgs) A formação de professores de línguas: Novos Olhares - Volume 2. Campinas, SP: Pontes Editores, 2013. pg. 209-230.

RUSSELL, D. R.; LEA, M.; PARKER, J.; STREET, B. V.; DONAHUE, T. Exploring Notions of Genre in "Academic Literacies" and "Writing across the Curriculum": Approaches across Countries and Contexts. In: BAZERMAN, C.; BONINI, A.; FIGUEIREDO, D. (Ed.). Genre in a Changing World. Fort Collins: The WAC Clearinghouse; West Lafayette: Parlor, 2009.

SOARES, M. Novas práticas de leitura e escrita: letramento na cibercultura. Educação \& Sociedade, Campinas, v. 23, n. 81, p. 143-160, Dez. 2002. Disponível em: <http:// dx.doi.org/10.1590/S0101-73302002008100008>. Acesso em: 26 set. 2010.

STREET, B. Literacy in theory and practice. London: Cambridge University Press, 1984.

What's "New" in New Literacy Studies? Critical approaches to literacy in theory and practice. Current Issues in Comparative Education. Teachers College, Columbia, University, 2003.

Dimensões "Escondidas" na Escrita de Artigos Acadêmicos. In: Revista Perspectiva. Florianópolis, v. 28, n. 2, 541-567, jul./dez. 2010. Disponível em: $<$ http://www.perspectiva.ufsc.br>. Acesso em 30 mar. 2012.

Eventos de letramento e práticas de letramento: teoria e práticas nos Novos Estudos do Letramento. In: MAGALHÃES, I. (org.). Discursos e práticas de letramento: pesquisa etnográfica e formação de professores. Campinas: Mercado de Letras, 2012a.

Literacy and Multimodality. STIS Lecture: Inter-Disciplinary Seminars Laboratório SEMIOTEC, da FALE/UFMG Faculdade de Letras, Belo Horizonte, Brasil, 2012b.

UNESCO. Informações sobre os projetos de formação de professores no Brasil apoiados pela UNESCO. 2006. Disponível em www.unesco.gob.br. Acessado em 12 de novembro de 2006.

VALADARES, Marcus G. P. F. V.; MURTA, Cláudia A. R. O Facebook como ambiente virtual de aprendizagem: liberdade e reapropriação no contexto educacional. Revista Texto Livre, [Belo Horizonte], v. 2, n. 3, 2012. Disponível em: <http://www.periodicos.letras.ufmg. br/index.php/ueadsl/article/view/3655>.

Acesso em: 01 abr. 2015.

WINGATE, U.; TRIBBLE, C. The Best of Both Worlds? Towards an English for Academic Purposes/Academic Literacies Writing Pedagogy. In: Studies in Higher Education, Vol. 37, No. 4, 06. 2012, p. 481-495.

Recebido em: 23/02/2016 Aceito em: 18/07/2016 